\title{
Изотопы углерода и кислорода в карбонатах карбонатитов Томторского REE - Nb месторождения (Арктическая Сибирь)
}

\author{
Пономарчук В.А. ${ }^{1}$, Жмодик С.М. ${ }^{2}$, Лазарева Е.В. ${ }^{2}$, Пыряев А.Н. ${ }^{2}$ \\ ${ }^{1}$ Институт геологии и минералогии СО РАН, Новосибирск, ponomar@igm.nsc.ru \\ ${ }^{2}$ Институт геологии и минералогии СО РАН, Новосибирск
}

Аннотация. Исследован изотопный состав углерода и кислорода в карбонатах из карбонатитов Томторского REE - Nb месторождения (Якутия). Образцы отбирались из 4 скважин $(115,117,4041,4849)$ по 2-9 штук с глубины от 120 до 200 метров. По карбонатам из скважин 115 и 117 произведена оценка $\delta^{13} \mathrm{C}(-2.8 \%$ \% $\mathrm{PDB})$, которая отвечает мантийному карбонатному источнику MCB (Giuliani et al., 2014). Bce породы скважин подверглись дейтерическим изменениям, о чем свидетельствует квазилинейный тренд расположения точек на $\delta^{13} \mathrm{C}-\delta^{18} \mathrm{O}$ диаграмме.

Ключевые слова: карбонатиты, Томторское REE - Nb месторождение, изотопы, углерод, кислород, мантия.

\section{Carbon and oxygen isotopes in the carbonatite carbonates of the Tomtor REE - Nb deposit (Arctic Siberia)}

\author{
Ponomarchuk V.A. ${ }^{1}$, Zhmodik S.M. ${ }^{2}$, Lazareva E.V. ${ }^{2}$, Pyryaev A.N. ${ }^{2}$ \\ ${ }^{1}$ Institute of Geology and Mineralogy SB RAS, Novosibirsk, ponomar@igm.nsc.ru \\ ${ }^{2}$ Institute of Geology and Mineralogy SB RAS, Novosibirsk
}

Annotation. The isotopic composition of carbon and oxygen in carbonates from carbonatites of the Tomtor REE - Nb deposit (Yakutia) was studied. Samples were taken from 4 wells $(115,117,4041,4849)$ in 2-9 pieces from a depth of 120 to 200 meters. For carbonates from wells 115 and 117 , an assessment of $\delta^{13} \mathrm{C}(-2.8 \%$ - PDB) was made, which corresponds to the mantle carbonate source MCB (Giuliani et al., 2014). All well rocks underwent deuteric alteration, as evidenced by the quasilinear trend of the location of points on the $\delta^{13} \mathrm{C}-\delta^{18} \mathrm{O}$ diagram.

Key words: carbonatites, Tomtor REE - Nb deposit, isotopes, carbon, oxygen, mantle.

Томторский комплекс ультраосновных щелочных пород и карбонатитов (ТК) на севере Республики Саха (Якутия) по многим параметрам уникален: это один из крупнейших подобных интрузивов, а богатые руды редких и редкоземельных элементов признаны природным концентраторатом. В региональном отношении ТК, располагается на пересечение двух крупных геологических структур - древнего Уджинского авлакогена ( 1074 млн. лет) [Гладкочуб и др., ] и Молодо-Попигайского вулканно-плутонического пояса триасового возраста, маркирующего разлом глубинного залегания. Обе структуры способны обеспечивать движение флюидов в периоды активизации. Геологическое строение ТК представлено в работах [Покровский и др., 1990; Kravchenko et al., 1995; Vladykin et al., 2014]. На данный момент установлено два основных магматических этапа, формирования пород ТК $-\sim 700$ и $\sim 400$ млн. лет (Vladykin et al., 2014). На всех породах карбонатитового ядра развита кора выветривания (КВ) со следующим профилем: карбонатиты - породы с преобладанием апатита (франколита)-гётита-сидерита. Породы КВ распределены неравномерно по площади карбонатитового ядра, все перечисленные типы наблюдаются в разрезах участков распространения уникально богатых руд (Северный, Южный и Буранный), (рис. 1). Рудная минерализация в неизмененных экзогенными процессами породах связана с карбонатитами, обогащенными флюидами. При кристаллизации карбонатитов и взаимодействии с вмещающими породами происходит отделение флюиднойафазы, которая, в свою очередь взаимодействует как с ранее образовавшимися породами магматической стадии, вмещающими породами (с возникновением фенитов), так и с карбонатитами, сформировавшимися на ранних стадиях. С отделением флюидов связаны явления дегазации, релеевского фракционирования, вторичных преобразований, каждый из которых меняют геохимический облик исходного карбонатитового расплава. При этом следует ожидать, что распределение 
изотопных и геохимических характеристик по нормали вглубь карбонатитового тела будет носить градиентный характер. Для проверки этого предположения проведено исследование неизменённых экзогенными процессами карбонатитов из керна скважин колонкового бурения, расположенных на различном расстоянии от внешних зон Томторского массива. Кроме того, $\delta^{13} \mathrm{C}$ и $\delta^{18} \mathrm{O}$ данные по удаленным от поверхности образцам позволяют сопоставить их с мантийными значениями $\delta^{13} \mathrm{C}$ и $\delta^{18} \mathrm{O}$, с целью уточнения источника карбонатитов.

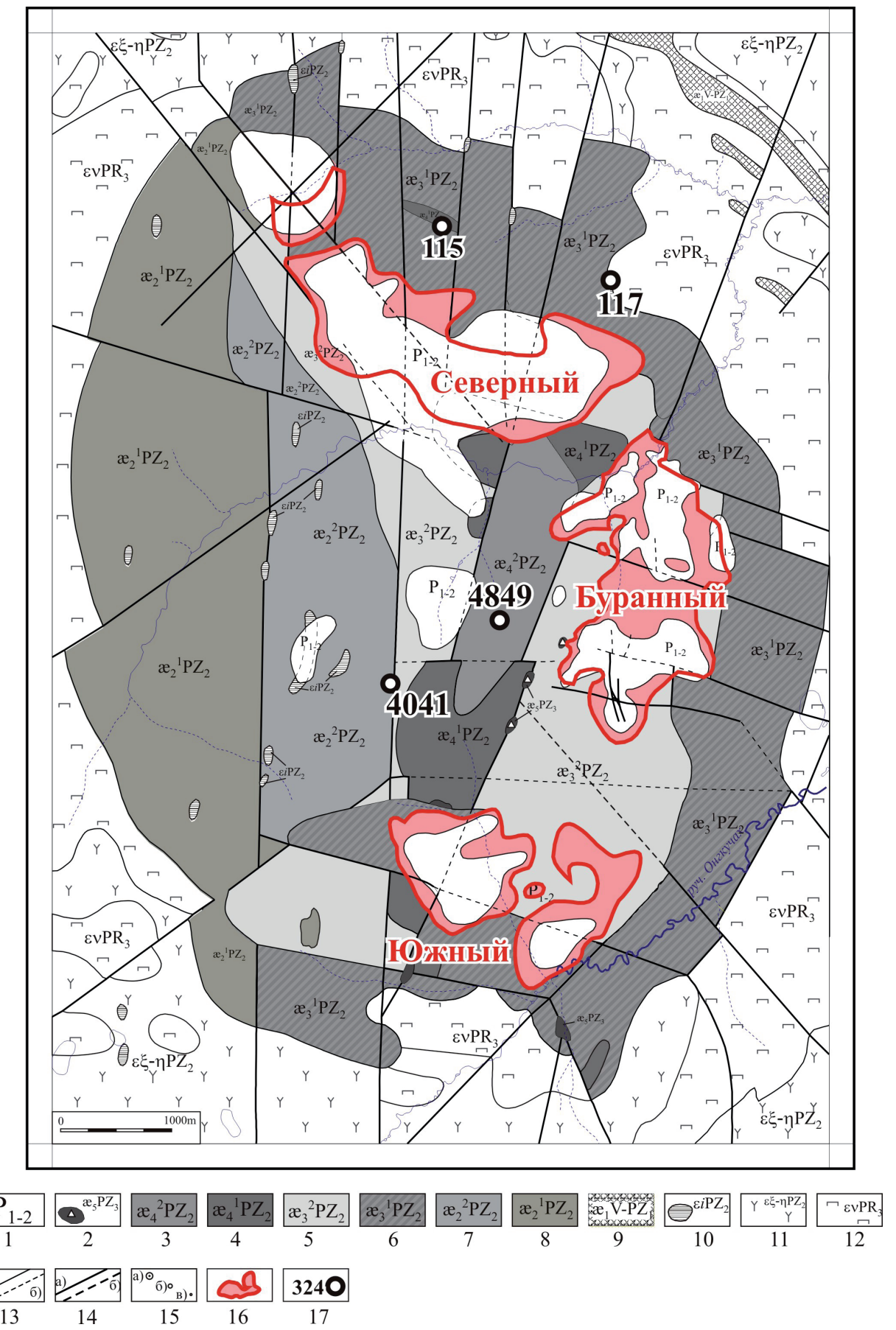

Рис. 1. Схематическая геологическая карта доюрских образований центральной части Томторского комплекса с положением скважин, условные обозначения см. в (Lasareva et al., 2015).

Fig. 1. Schematic geological map of the pre-Jurassic formations of the central part of the Tomtor complex with the position of the wells; see legend (Lasareva et al., 2015). 
Всего исследовано несколько десятков образцов из 5 скважин: 4849, 4041, 115, 117, 6151. В образцах определялся изотопный состав углерода и кислорода. Учитывая совместное присутствие в образцах кальцита и доломита/анкерита, для определения $\delta^{13} \mathrm{C}$ и $\delta^{18} \mathrm{O}$ в каждой из карбонатных фаз использовалось дифференциальное разложение образцов в обезвоженной ортофосфорной кислоте (Al-Aasm et al., 1990). Длительность реакции растворения для кальцита составляла - 1 час, для доломита/анкерита - 24 часа. Анализ $\delta^{13} \mathrm{C}$ и $\delta^{18} \mathrm{O}$ проводился на масс-спектрометре МАТ-253 в проточном режиме гелием в токе гелия? особой чистоты. Для пробоподготовки использовался блок GasBanch. Температура разложения образцов составляла $70^{\circ} \mathrm{C}$. Значения $\delta^{13} \mathrm{C}$ и $\delta^{18} \mathrm{O}$ углерода представлены в \%о относительно стандарта PDB, кислорода - SMOW. Результаты анализа приведены в таблице 1 и на рисунке 2 .

Таблица 1. Изотопные составы $\delta^{13} \mathrm{C}$ и $\delta^{18} \mathrm{O}$ карбонатов.

Table 1. Isotopic compositions of $\delta^{13} \mathrm{C}$ and $\delta^{18} \mathrm{O}$ carbonates.

\begin{tabular}{|c|c|c|c|c|c|}
\hline \multirow{2}{*}{ Название } & \multirow{2}{*}{ Отбор, м } & \multicolumn{2}{|c|}{ Кальцит } & \multicolumn{2}{|c|}{ Дол. /анкерит } \\
\hline & & $\delta^{13} \mathrm{C}$ & $\delta^{18} \mathrm{O}$ & $\delta^{13} \mathrm{C}$ & $\delta^{18} \mathrm{O}$ \\
\hline \multicolumn{6}{|c|}{ Скважина 4849} \\
\hline TM-469 & $\sim 120$ & 0.3 & 19.6 & 0.4 & 19.9 \\
\hline TM-448 & 125 & 1.1 & 19.3 & 0.0 & 19.9 \\
\hline TM-451 & 128 & 0.2 & 18.6 & -0.7 & 19.8 \\
\hline TM-452 & 128.5 & 0.5 & 18.1 & 0.3 & 19.8 \\
\hline TM-454 & 130-132 & -4.5 & 17.3 & -8.9 & 18.0 \\
\hline TM-455 & $130-132$ & -2.3 & 17.8 & -3.4 & 18.5 \\
\hline TM-456 & $130-132$ & -1.8 & 17.7 & -3.8 & 19.6 \\
\hline TM-476 & 199-202 & -2.0 & 18.0 & -2.5 & 19.6 \\
\hline \multicolumn{6}{|c|}{ Скважина 4041} \\
\hline TM-577 & 157,5 & -3.2 & 14.2 & -3.7 & 16.6 \\
\hline TM-579 & $\sim 160$ & -3.6 & 14.6 & -4.0 & 17.3 \\
\hline ТМ-579д & & -2.7 & 12.9 & -3.6 & 16.2 \\
\hline TM-581 & 162,7 & -3.7 & 13.9 & -3.8 & 16.7 \\
\hline TM-497 & 197 & 0.5 & 18.1 & 0.3 & 19.8 \\
\hline \multicolumn{6}{|c|}{ Скважина 115} \\
\hline TM-416 & 190 & -3.1 & 12.2 & -2.9 & 13.3 \\
\hline TM-417 & & -3.2 & 10.1 & -3.8 & 12.5 \\
\hline TM-419 & & -3.2 & 13.1 & -4.8 & 7.1 \\
\hline TM-435 & & -2.9 & 9.4 & -3.1 & 13.1 \\
\hline TM-436 & 199 & -2.5 & 14.9 & -3.8 & 17.0 \\
\hline \multicolumn{6}{|c|}{ Скважина 117} \\
\hline TM-408 & & -2.9 & 11.3 & -2.9 & 12.0 \\
\hline TM-409 & & -2.1 & 9.0 & -3.5 & 12.9 \\
\hline
\end{tabular}

Перед обсуждением результатов анализа отметим, что для карбонатитов изотопы С и О являются важными инструментом для верификации мантийного источника и выявления пост- и послемагматических процессов в них. Традиционным критерием принадлежности к мантийным выплавкам является топологическая совмещенность значений $\delta^{13} \mathrm{C}$ и $\delta^{18} \mathrm{O}$ с «боксом Тейлора» (в дальнейшем аббревиатура ВT), который ограничен интервалами от -3.1 до $-7.7 \%$ для $\delta^{13} \mathrm{C}$ и $\delta^{18} \mathrm{O}(\mathrm{SMOW})$ от +5.3 до $+8.4 \%$ (Taylor et al., 1967). Эти интервалы были рекомендованы на основе данных и представлений о составе мантии, более полувековой давности. В результате продолжительных дискуссий, с обсуждением также регионального аспекта, предложена коррекция интервалов изотопов С и О для характеристики мантии значениями $-2 \%$ o $>\delta^{13} \mathrm{C}>-8 \%$ и $6 \%$ o $>\delta 18 \mathrm{O}>9 \%$, названный мантийным карбонатным боксом (mantle carbonate box - MCB) (Giuliani et al., 2014). 


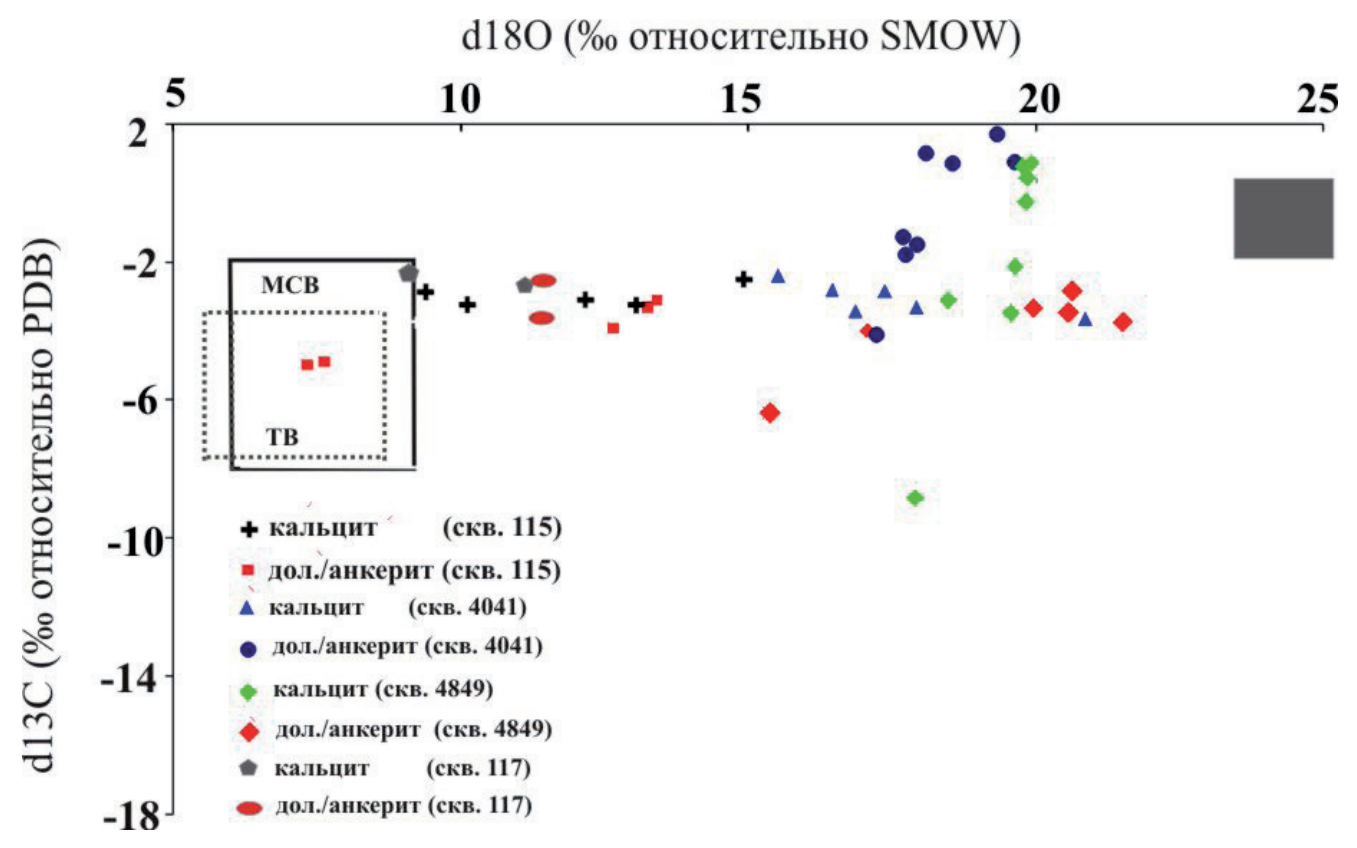

Рис. 2. $\delta^{13}$ С и $\delta^{18} \mathrm{O}$ диаграмма для карбонатитов скважин $115,117,4041,4849$. Обозначения: ТВ - «Бокс Туйлоpa» (пунктирная линия) (Taylor et al., 1967), MCB - мантийныq карбонатныq бокс (сплошная линия) (Giuliani et al., 2014), черный квадрат - осадочные известняки.

Fig. 2. $\delta^{13} \mathrm{C}$ and $\delta^{18} \mathrm{O}$ diagram for well carbonatites $115,117,4041,4849$. Designations: TB - Taylor Box (dashed line) (Taylor et al., 1967), MCB - mantle carbonate box (solid line) (Giuliani et al., 2014), black square - sedimentary limestones.

Значения $\delta^{13} \mathrm{C}$ и $\delta^{18} \mathrm{O}$ карбонатов из различных карбонатитовых комплексов обычно характеризуются значительным разбросом на $\delta^{13} \mathrm{C}-\delta^{18} \mathrm{O}$ диаграмме, существенно превышающим значения как бокса Тейлора, так мантийного карбонатного бокса. Это обусловлено влиянием многочисленных автометасоматических и постмагматических процессов (релеевское фракционирование, низкотемпературное и высокотемпературное изменение флюидами, дегазация, контаминация и др.). Тренды поведения $\delta^{13} \mathrm{C}$ и $\delta^{18} \mathrm{O}$ - значений в результате проявления каждого процесса известны, однако, при совмещении двух или нескольких процессов, как например, релеевского фракционирования и контаминации карбонатитов осадочными сланцами, идентификация процессов затруднена.

Приведенные в таблице1 данные, проиллюстрированые на рисунке 2, позволяют сделать несколько выводов.

1) Значения $\delta^{13} \mathrm{C}$ карбонатитов скважин $115,117,4041$ имеют незначительный разброс $~ 1.5 \%$. Среднее значение по $\delta^{13} \mathrm{C}$ карбонатитов по этим скважинам составляет $-2.8 \%$ и указывает на мантийный источник (МСB).

2) $\delta^{13} \mathrm{C}$ доломит/анкеритовой фазы скважин 115 и 117 совпадают с $\delta^{13} \mathrm{C}$ кальцитовой фазы.

3) $\delta^{18} \mathrm{O}$ кальцитовой фазы карбонатов скважин 115 и 117 характеризуются широким интервалом - от 9 до 13 \%, что свидетельствует о фракционировании изотопов кислорода. Температурный диапазон фракционирования, рассчитанный по формулам, представленным в работе (Yong-Fei Zheng. , 1999) составляет от 400 до $250^{\circ} \mathrm{C}$.

4) Интерпретация изотопных и геохимических данных образцов скважины 4849 более сложная. Повышенные значения $\delta^{13} \mathrm{C}$, как например ТМ-469, ТМ-448, Тм-451, ТM-452, обычно объясняются контаминацией углеродом осадочных близлежащих пород, мраморов. Скважина 4849 пробурена в центральной части Томторского комплекса и, судя по результатам разведочного бурения, вблизи мраморов и осадочных пород нет. Кроме того, первичные изотопные составы стронция всех образцов этой скважины находятся в узком интервале 0.7034-0.7037, что исключает значимую добавку корового первичного изотопного состава стронция. Для понимания ситуации здесь требуются дополнительные исследования, но, очевидно, что процессы релеевского фракционирования, низ- 
котемпературного и высокотемпературного изменения флюидов и дегазации не могли привести к столь значительным изенениям изотопного состава кислорода.

Работа выполнена в рамках гранта № 18-17-00120 Российского Научного Фонда. Аналитические работы выполнены в ЦКП Многоэлементных и изотопных исследований СО РАН. Исследования проводились согласно планам НИР Института геологии и минералогии.

\section{Литература}

1. Гладкочуб Д.П., Станевич А.М., Травин А.В. и др. Уджинский мезопротерозойский палеорифт (Север Сибирского кратона): новые данные о возрасте базитов, стратиграфии и микрофитологии //ДАН. 2009. Т. 425. № 5. C. 642-648. https://doi.org/10.1134/S1028334X090300.

2. Покровский Б.Г., Беляков А.Ю., Кравченко С.М. и др. Происхождение карбонатитов и рудной толщи массива Томтор (Северо-Западная Якутия) по изотопным данным // Геохимия. 1990. № 9. С. 1320-1329.

3. Al-Aasm I.S., Taylor B.E., South B. Stable isotope analysis of multiple carbonate samples using selective acid extraction // Chemical Geology. 1990. V. 80. P. 119-125. doi.org/https://doi.org/10.1016/01689622(90)90020-D.

4. Giuliani A., Phillips, Kamenetsky V.S., Fiorentini M.L., Farquhar J., Kendrick M.A. Stable isotope (C, O, S) compositions of volatile-rich minerals in kimberlites: A review // Chemical Geology. V. 374-375. 2014. P. 61-83.

5. Yong-Fei Zheng. Oxygen isotope fractionation in carbonate and sulfate minerals // Geochemical Journal. 1999 V. 33. P. 109-126.

6. Kravchenko S.M., Pokrovsky B.G. The Tomtor alkaline ultrabasic massif and related REE-Nb deposits, northern Siberia // Econ. Geol. 1995. V. 90. N. 3. P. 676-689. https://doi.org/10.2113/gsecongeo.90.3.676.

7. Lazareva E.V., Zhmodik S.M., Dobretsov N.L. et al. Main minerals of abnormally high-grade ores of the Tomtor deposit (Arctic Siberia). Rus. Geol. and Geoph. 2015. N. 56 (6). P. 844-873. https://doi.org/10.15372/ GiG20150603.

8. Sam Broom-Fendley, Timothy Heaton, Frances Wall, GusGunn. Tracing the fluid source of heavy REEmineralisation in carbonatites using a novel method of oxygen-isotope analysis in apatite: The example of Songwe Hill, Malawi // Chemical Geology. 2016. V. 440. P. 275-287.

9. Taylor H.P., Frechen J., Degens E.T. Oxygen and carbon isotope studies of carbonatites from the Laacher See district, West Germany and the Alnö district, Sweden. Geochim. Cosmochim. 1967. Acta 31. P. 407-430.

10. Vladykin N.V., Kotov A.B., Borisenko A.S., Yarmolyuk V.V., Pokhilenko N.P., Sal'nikova E.V., Travin F.V. Yakovleva S.Z. Age boundaries of formation of the Tomtor alkaline-ultramafic pluton: U-Pb and 40Ar/39Ar geochronological studies // Doklady Earth Sci. 2014. V. 454. P. 7-11. https://doi.org/10.1134/ S1028334X14010140. 